\title{
Scribe Width Optimization of Absorber Laser Ablation for Thin-film Silicon Solar Modules
}

\author{
Bugra TURAN ${ }^{* 1}$, Stefan HAAS ${ }^{* 1}$ \\ ${ }^{* 1}$ Forschungszentrum Jülich GmbH, IEK5 - Photovoltaik, 52425 Jülich, Germany \\ E-mail: b.turan@fz-juelich.de
}

\begin{abstract}
The scribe width reduction of the absorber removal process for the integrated series connection of thin-film silicon solar modules was investigated with laser-induced back-side ablation. Depending on the used scribing beam spot radius and absorber thickness changes of ablation behavior lead to limitations of the scribe width reduction. The influence of the laser processes on the electrical properties between front- and back-contact was characterized with Transmission Line Method measurements. The values of the interconnection resistance between front- and back-contact are used in electrical calculations to estimate the optimal trade-off between increase of active cell area with thinner scribe lines and the increase of series resistance losses from interconnection resistance formation. Calculations predict a $\sim 1 \%$ relative decrease of module losses for the optimized processes compared to commonly used processes from industry.
\end{abstract}

DOI: 10.2961/jlmn.2013.03.0009

Keywords: Thin-tilm, photovoltaic, solar cell, modules, laser ablation, nanosecond, interconnection

\section{Introduction}

Large deposition techniques for substrates with sizes of up to $5.7 \mathrm{~m}^{2}$ are commonly used in thin-film photovoltaic industry. This enables the production of solar cells with low $\$ / \mathrm{W}$ values. In contrast to c-Si solar cell wafer technology, a cell series connection can be integrated between the deposition processes and be realized monolithically on the substrate. Due to the series connection the output voltage of the module is increased while the Ohmic losses in the contact materials are decreased. For thin-film silicon solar modules the integrated series connection is realized by three layer removal steps. The first step is the front-contact separation process (P1). This is followed by the interconnection between front- and back-contact of two adjacent cell stripes (P2). Finally, back-contact insulation is required to create the individual cells (P3). In each step nanosecond laser ablation is commonly used for the removal processes. Figure 1 shows a simplified sketch of a solar cell with two adjoining series connections.

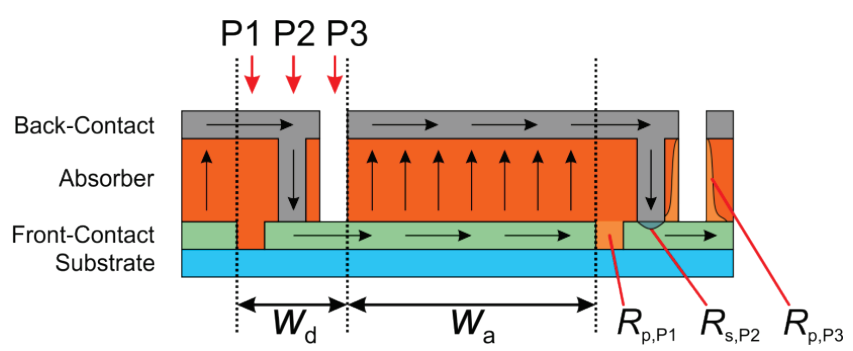

Fig. 1 Schematic sketch of an interconnected thin-film solar module with interconnection region depicted by $w_{\mathrm{d}}$ and active cell region $w_{\mathrm{a}}$. Resistances $R_{\mathrm{p}, \mathrm{P} 1}$ and $R_{\mathrm{p}, \mathrm{P} 3}$ are shunts created by processes $\mathrm{P} 1$ and P3. A series resistance $R_{\mathrm{s}, \mathrm{P} 2}$ between front- and back-contact of two adjacent cells is formed by $\mathrm{P} 2$.
However, the area needed for the interconnection is no longer available for current generation and is depicted by the dead area width $w_{\mathrm{d}}$ in Figure 1. An area loss fraction $f_{\mathrm{d}}$ can be defined by the ratio between active cell width $w_{\mathrm{a}}$ and overall width $w_{\mathrm{a}}+w_{\mathrm{d}}$. Along with this dead area loss fraction we can estimate the Ohmic losses in the front-contact $f_{\mathrm{FC}}$ as followed,

$$
f_{\mathrm{d}}=\frac{w_{\mathrm{d}}}{w_{\mathrm{a}}+w_{\mathrm{d}}} \text { (1) } \quad f_{\mathrm{FC}}=-\frac{J_{\mathrm{MPP}}}{U_{\mathrm{MPP}}} \frac{R_{\mathrm{SH}}}{3} \frac{w_{\mathrm{a}}^{3}}{w_{\mathrm{a}}+w_{\mathrm{d}}}
$$

Here, $J_{\mathrm{MPP}}$ and $U_{\mathrm{MPP}}$ are the current density and voltage in the maximum power point [1]. The value $R_{\mathrm{SH}}$ is the front-contact sheet resistance. If we plot the sum of both fractional losses against the active cell stripe width $w_{\mathrm{a}}$ an optimal cell stripe width $w_{\mathrm{a} \text {,opt }}$ can be identified for a certain interconnection width $w_{\mathrm{d}}$. Figure 2 shows these calculations for a thin-film silicon tandem solar module with different interconnection widths $w_{\mathrm{d}}$.

It can be seen that a decrease of $w_{\mathrm{d}}$ will significantly decrease the dead area fraction $f_{\mathrm{d}}$ and increase the overall module efficiency. The relative module loss fraction $f$ at the optimal cell stripe width $w_{\text {a,opt }}$ (see stars in Fig. 2) is decreased from $5 \%$ to approximately $2 \%$.

Along with an inevitable loss of active area there are also possible deteriorations of electrical properties caused by the non-ideal laser ablation removal processes. Each process can generate electrical shunts or series resistances (see right side of Fig. 1). The processes P1 and P3 can create shunts $\left(R_{\mathrm{p}, \mathrm{P} 1}\right.$ and $\left.R_{\mathrm{p}, \mathrm{P} 3}\right)$ while $\mathrm{P} 2$ processing creates a series resistance between front- and back-contact due to 
contact resistance formation at the interface of the interconnection $\left(R_{\mathrm{s}, \mathrm{P} 2}\right)$.

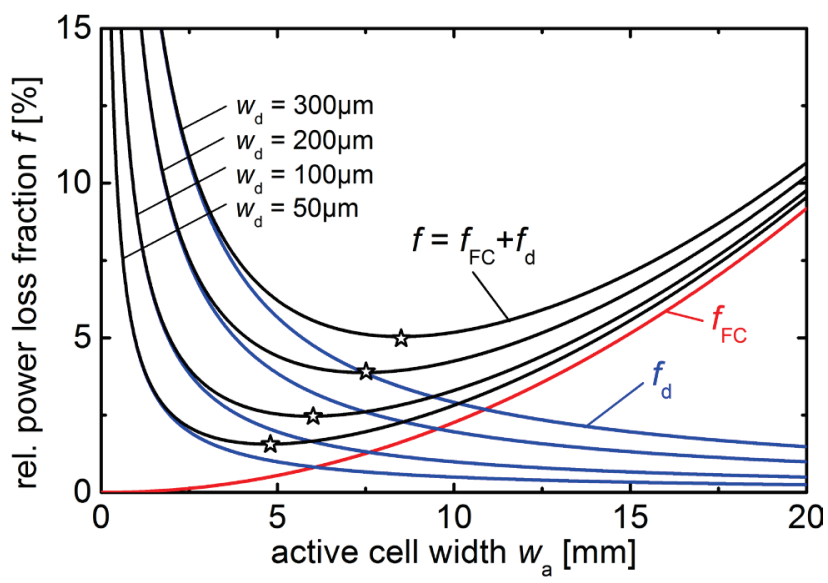

Fig. 2 Calculation of module losses for a tandem solar cell with different interconnection widths $w_{\mathrm{d}}$. Stars mark the optimal cell stripe width $w_{\mathrm{a}, \text { opt }}$ for interconnection widths $w_{\mathrm{d}}=300 \mu \mathrm{m}, 200 \mu \mathrm{m}, 100 \mu \mathrm{m}$, and $50 \mu \mathrm{m}$. For $f_{\mathrm{FC}}$ a sheet resistance of $R_{\mathrm{SH}}=8 \Omega$ was used. Solar cell parameters are: $J_{\mathrm{MPP}}=-9.7 \mathrm{~mA} / \mathrm{cm}^{2}$ and $U_{\mathrm{MPP}}=1.1 \mathrm{~V}$.

This work reports on the scribe width reduction of the interconnection processing step P2 for the series connection of thin-film silicon solar modules and the impact of width reduction on $R_{\mathrm{S}, \mathrm{P} 2}$. In literature the main focus of investigations for P2 lie on the proper removal of the absorber layer without residuals on the front-contact. Bovatsek et. al studied the threshold behavior for absorber removal with different laser beam radii and pulse durations [2]. Lauzurica et. al investigated the front-contact surface after P2 scribing with EDX and observed silicon accumulation [3]. Ku et. al found out with XPS and SIMS measurements that $\mathrm{SiO}$ formation on the front- and backcontact interface can have an negative impact on the value of $R_{\mathrm{s}, \mathrm{P} 2}$ [4]. Simulations on the optimal cell geometries including the electrical influence of the P2 interconnection was done by Brecl et. al [5]. No investigations on the impact of scribe width reductions on the electrical properties of the solar module were found. This includes the influence of the scribe width reduction on cell deterioration from laser processing.

The geometrical width reduction limits for $\mathrm{P} 2$ will be investigated for substrate side processing of various absorber thicknesses. The process is called laser-induced back-side ablation and is realized by illumination through the glass substrate side. Due to the high differences of the absorption coefficients $\alpha$ in each layer a high amount of the laser pulse energy is absorbed in a confined region in the silicon starting at the front-contact/absorber interface. This process generates high mechanical forces in the absorber layer which leads to structural disintegration and kinetic removal of the mostly solid material. Therefore, such processes are often called laser spallation or laser lift-off [6]. Due to this mechanically dominated ablation behavior of laser-induced back-side ablation it is possible that the ablation properties change depending on the used beam spot radius in focus $w_{0}$ and/or absorber layer thickness $d_{\text {abs. }}$.

With the formation of the series resistance $R_{\mathrm{s}, \mathrm{P} 2}$ it is expected that its value increases with a decrease of the scribe width $w_{\mathrm{P} 2}$ due to the geometrical reduction of the contact area. It is important to identify if the increase $R_{\mathrm{s}, \mathrm{P} 2}$ is solely caused by this decrease of contact area or if changes of the specific contact resistance $\rho_{c}$ arise.

The paper shows that for P2 processing a clear correlation between laser parameters and contact resistivity can be found. The process window for optimized contact resistances depend on the values of $w_{0}$ as well as on the absorber thickness $d_{\mathrm{abs}}$ and atmospheric conditions during laser scribing.

\section{Methods}

\subsection{Sample preparation}

A commercial laser processing tool from Baasel/ROFIN was used for all experiments. The split-axis machine is capable of feed-rates $v$ of up to $1000 \mathrm{~mm} / \mathrm{s}$ in the $\mathrm{X}-\mathrm{Y}$ directions. A nanosecond diode-pumped $\mathrm{Nd}: \mathrm{YVO}_{4}$ solid-state laser source with a wavelength $\lambda$ of $532 \mathrm{~nm}$ (SHG) and a pulse duration $\tau$ between $11 \mathrm{~ns}-34 \mathrm{~ns}$ is integrated in the processing tool. A maximum average output power $P_{\max }$ of $3 \mathrm{~W}$ and repetition rates $f_{\mathrm{PRF}}$ of $1 \mathrm{kHz}-100 \mathrm{kHz}$ can be used. The laser beam is directed onto the sample through the glass substrate side with fixed lens systems. Different focal lengths $f$ of $300 \mathrm{~mm}, 116 \mathrm{~mm}$, and $56 \mathrm{~mm}$ were used. Their associated laser beam radii in focus $w_{0}$ were approx. $60 \mu \mathrm{m}, 20 \mu \mathrm{m}$ and $10 \mu \mathrm{m}$ which were measured with a beam profiler (MicroSpotMonitor from PRIMES). Figure 3 shows the respective laser beam profiles in focus extracted from the measurement system each with the corresponding Gaussian curve fit.

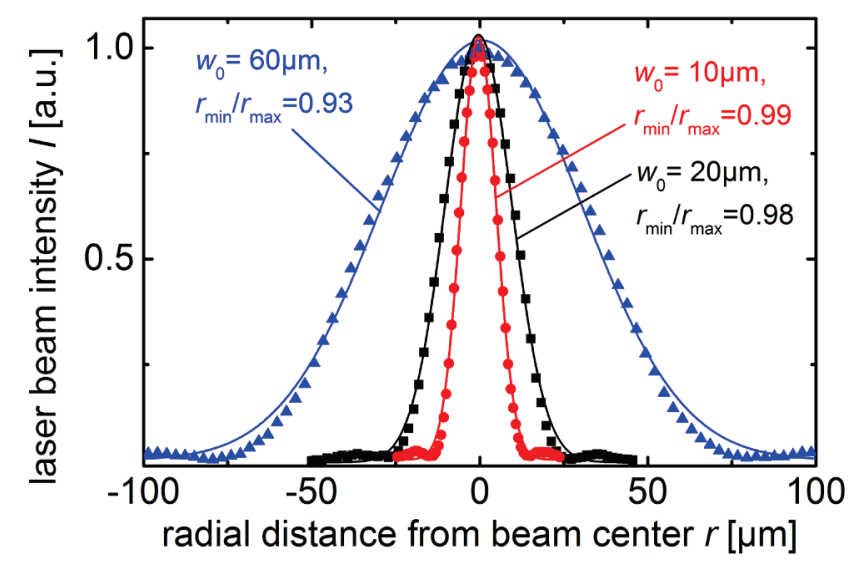

Fig. 3 Measured laser beam profiles in focus for different focusing optics. The focal lengths are $f=300 \mathrm{~mm}(\boldsymbol{\Delta})$, $116 \mathrm{~mm}(\bullet)$, and $56 \mathrm{~mm}(\bullet)$. The solid lines represent simple Gaussian curve regressions of the measurement data. The laser beam radii $w_{0}$ is defined where intensity drops by $86 \%$ of the peak intensity $\left(1 / \mathrm{e}^{2}\right)$. Ellipticity $r_{\min } / r_{\max }$ was extracted by $2^{\text {nd }}$ Moment method.

The measurement of the laser beam in focus shows a good Gaussian behavior of the intensity distribution as expected. Furthermore, ellipticity of the beam is negligible. The average laser power $P_{\text {avg }}$ was measured with a thermopile sensor system. The laser pulse fluence is defined as $F_{\mathrm{p}}=2 E_{\mathrm{p}} / \pi w_{0}^{2}$ with the pulse energy $E_{\mathrm{p}}=P_{\mathrm{avg}} / f_{\mathrm{PRF}}$. 
For processing, $3 \mathrm{~mm}$ thick float-glass substrates with $900 \mathrm{~nm}$ thick $\mathrm{SnO}_{2}: \mathrm{F}$ front-contact material, a transparent conductive oxide (TCO), from the Asahi Glass Company (type ANS14 ME) were used. On top of these substrates an amorphous silicon (a-Si:H) p-i-n solar cell with a thickness of $300 \mathrm{~nm}$ or a combination of amorphous silicon (a-Si:H) and microcrystalline silicon ( $\mu \mathrm{c}-\mathrm{Si}: \mathrm{H})$, a tandem solar cell, with a thickness of $1.4 \mu \mathrm{m}$ was deposited via Plasma Enhanced Chemical Vapor Deposition (PECVD) [7]. To investigate the influence of the atmospheric conditions on the contact, $\mathrm{P} 2$ processing was also done in a vacuum chamber with a pressure of $1.5 \times 10^{-5} \mathrm{mbar}$.

\subsection{Characterization}

The ablation threshold of the investigated material system/scribing setup was determined with a well-known method proposed by Liu [8]. Originally this method was meant to determine the threshold of material change for processing of highly homogenous bulk material like crystalline silicon from the film-side. Although extended to processing of thin films, multi-layer stacks characterization is most likely problematic due to different material properties throughout the layer stack. In the case of laserinduced back-side scribing the onset pulse energy $E_{\mathrm{p}, \text { on }}$ gives additional information for interpretation of the measurements. This is the minimal necessary pulse energy at which ablation occurs [6].

Optical microscope images were used to determine the visible quality of the optimized scribe lines. Possible debris redeposition and surface morphology at the scribe edge was identified after back-contact deposition.

The function of the P2 scribe is the electrical interconnection of two adjacent cell stripes. The front-contact of one cell is connected with the back-contact of the next cell. During processing, the absorber is selectively removed and the interconnection is realized by the back-contact deposition into the scribe. It is therefore from utter importance to have a good electrical contact between front- and back-contact. In our case a combination of sputtered aluminum-doped zinc oxide ( $\mathrm{ZnO}: \mathrm{Al})$, silver and, again, $\mathrm{ZnO}: \mathrm{Al}$ is used as back-contact material. Since the contact resistance is not directly measureable, a special test procedure is needed for an accurate evaluation. Figure 4 shows the test-structure for an IV-measurement after P2 processing and back-contact deposition.

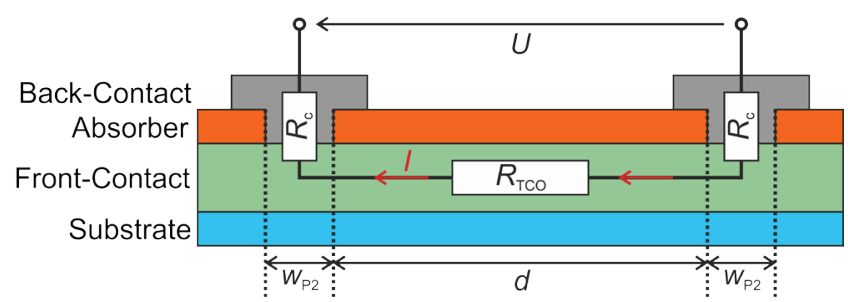

Fig. 4 Measurement setup for determination of the contact resistance $R_{c}$ with Transmission Line Method (TLM) with variable distance $d$ between two $\mathrm{P} 2$ scribe lines. Here $w_{\mathrm{P} 2}$ corresponds to the $\mathrm{P} 2$ scribing width.

The total resistance $R_{\text {Total }}=U / I$ from Fig. 4 can be described as followed,

$$
R_{\text {Total }}=R_{\mathrm{TCO}}+2 \cdot R_{\mathrm{c}}=\frac{R_{\mathrm{SH}}}{W} \cdot d+2 \cdot R_{\mathrm{c}}
$$

Here, $W$ is the width of the contact out-of-plane and $R_{\mathrm{SH}}$ is the TCO sheet resistance. The resistance $R_{\mathrm{TCO}}$ is linearly dependent on the distance $d$ between the two contacts. Thus, if the total resistance $R_{\text {Total }}$ is measured for different contact distances $d$ a linear behavior is obtained. The extrapolation of $R_{\text {Total }}$ with the y-axis intercept will yield two times the contact resistance $R_{\mathrm{c}}$. In literature this method is known as Transfer Line Method or Transfer Length Method (TLM) introduced by Shockley [9]. For the evaluation of the specific contact resistance $\rho_{\mathrm{c}}$ between the front- and the back-contact it is not possible to simply multiply $R_{\mathrm{c}}$ with the contact area $A=w_{\mathrm{P} 2} \cdot W$ since for our geometry the TCO thickness $d_{\mathrm{TCO}}$ is much smaller than the scribe width $w_{\mathrm{P} 2}$. Hence, current crowding beneath the contacts occurs. From transmission line theory we can conclude [10] that the contact resistance $R_{\mathrm{c}}$ can be evaluated by,

$R_{\mathrm{C}}=\frac{\lambda_{\mathrm{T}} \cdot R_{\mathrm{SH}}}{W} \cdot \operatorname{coth}\left(\frac{w_{\mathrm{P} 2}}{\lambda_{\mathrm{T}}}\right)=\frac{\sqrt{\rho_{\mathrm{c}} \cdot R_{\mathrm{SH}}}}{W} \cdot \operatorname{coth}\left(\frac{w_{\mathrm{P} 2}}{\lambda_{\mathrm{T}}}\right)$

with,

$$
\lambda_{\mathrm{T}}=\sqrt{\frac{\rho_{\mathrm{c}}}{R_{\mathrm{SH}}}}
$$

Here, $R_{\mathrm{SH}}$ is, again, the sheet resistance and $W$ the width of the contact in out-of-plane direction. Furthermore, $w_{\mathrm{P} 2}$ is the contact length and $\lambda_{\mathrm{T}}$ is the transfer length which is defined by $R_{\mathrm{SH}}$ and the specific contact resistance $\rho_{\mathrm{c}}$. The transfer length can be evaluated from the intersection between the extrapolated total resistance $R_{\text {Total }}$ and the $\mathrm{x}$-axis. With Equation (4) it is possible to numerically evaluate the specific contact properties $\rho_{c}$. For the measurement a test-structure design with eight contacts and a distance $d$ of $1 \mathrm{~cm}$ between each contact were processed. The width $W$ of every contact was $1 \mathrm{~cm}$ as well. Mesa definition of the front-contact and absorber at the edges provide uniform current flow in $x$ direction.

A Keithley 2400 series SourceMeter is used in 4 -Terminal mode sourcing a voltage of $-0.5 \mathrm{~V}$ to $0.5 \mathrm{~V}$ with a step-size of $50 \mathrm{mV}$. To minimize the influence of non-uniform sheet resistance values and contact property deviations measurements were conducted with a permutation of every terminal combination. For eight terminals this leads to 28 combinations. Seven with a distance $d$ of $1 \mathrm{~cm}$, six with $2 \mathrm{~cm}$, five with $3 \mathrm{~cm}$, and so on.

For a better reference a definition list of parameters used in this work is given below in Table 1. 
Table 1 Definition list of the major parameters used in this work for reference.

\begin{tabular}{|c|c|c|}
\hline $\begin{array}{l}\text { Parameter } \\
\text { abbreviation }\end{array}$ & Description & $\begin{array}{l}\text { Typical } \\
\text { unit }\end{array}$ \\
\hline$w_{\mathrm{a}}, w_{\mathrm{d}}$ & Active/dead cell width & $\mathrm{mm}$ \\
\hline$w_{\mathrm{P} 2}$ & P2 laser scribe width & $\mu \mathrm{m}$ \\
\hline$f_{\mathrm{d}}, f_{\mathrm{FC}}, f_{\mathrm{P} 2}$ & $\begin{array}{c}\text { Fractional module } \\
\text { losses }\end{array}$ & - \\
\hline$R_{\mathrm{p}, \mathrm{P} 1}, R_{\mathrm{s}, \mathrm{P} 2}, R_{\mathrm{p}, \mathrm{P} 3}$ & Parasitic resistances & $\Omega$ \\
\hline$U_{\mathrm{MPP}}$ & $\begin{array}{l}\text { Cell voltage in the } \\
\text { maximum power point }\end{array}$ & V \\
\hline$J_{\mathrm{MPP}}$ & $\begin{array}{l}\text { Current density in the } \\
\text { maximum power point }\end{array}$ & $\mathrm{mA} / \mathrm{cm}^{2}$ \\
\hline$R_{\mathrm{SH}}$ & TCO sheet resistance & $\Omega$ \\
\hline$R_{\text {Total }}$ & Total TLM resistance & $\Omega$ \\
\hline$R_{\mathrm{c}}, R_{\mathrm{c}, \text { min }}$ & Contact-resistance & $\Omega$ \\
\hline$\rho_{\mathrm{c}}$ & $\begin{array}{l}\text { Specific contact } \\
\text { resistance for } P 2\end{array}$ & $\Omega \mathrm{mm}^{2}$ \\
\hline$\lambda_{\mathrm{T}}$ & Current transfer length & $\mu \mathrm{m}$ \\
\hline$W, d$ & $\begin{array}{l}\text { Contact width and } \\
\text { distance for TLM }\end{array}$ & $\mathrm{mm}$ \\
\hline$w_{0}$ & Beam radius in focus & $\mu \mathrm{m}$ \\
\hline$E_{\mathrm{p}, \mathrm{on}}, E_{\mathrm{p}}$ & (Onset) pulse energy & $\mu \mathrm{J}$ \\
\hline$F_{\mathrm{p}, \mathrm{on}}, F_{\mathrm{p}}$ & (Onset) pulse fluence & $\mathrm{J} / \mathrm{cm}^{2}$ \\
\hline$E_{0}$ & Unit scaling factor & $\mathrm{J}$ \\
\hline$D^{2}$ & Squared crater diameter & $\mu \mathrm{m}^{2}$ \\
\hline$E_{\mathrm{th}}$ & $\begin{array}{c}\text { Extrapolated threshold } \\
\text { energy }\end{array}$ & $\mu \mathrm{J}$ \\
\hline$f_{\mathrm{PRF}}$ & $\begin{array}{l}\text { Pulse repetition } \\
\text { frequency }\end{array}$ & $\mathrm{kHz}$ \\
\hline$v$ & Scribe line feed-rate & $\mathrm{mm} / \mathrm{s}$ \\
\hline
\end{tabular}

\section{Results and discussion}

\subsection{Ablation behavior}

Before reduction of the scribing width is carried out, the ablation behavior of the used material systems was investigated. The influence of the beam spot radius $w_{0}$ on the ablation of the absorber and ablation of the underlying TCO layer was determined with a method proposed by Liu [8]. Figures 5-7 show plots of the squared crater diameter $D^{2}$ vs. the natural logarithm of the pulse energy $E_{\mathrm{p}}$ (scaled by $E_{0}=1 \mathrm{~J}$ for unit removal) for single-spot ablation of a$\mathrm{Si}: \mathrm{H}(300 \mathrm{~nm})$ and tandem $(1.4 \mu \mathrm{m})$ absorber materials on $\mathrm{SnO}_{2}: \mathrm{F} \mathrm{TCO}$ with different laser beam spot sizes processed through the glass substrate side. Furthermore, undesired ablation of the underlying TCO layer beneath the tandem absorber is plotted as well. TCO ablation is not plotted for samples with a-Si:H layer since only few processing parameters lead to TCO ablation. The ablation behavior of the TCO defines a boundary for the laser process where selective ablation of the absorber material is possible.

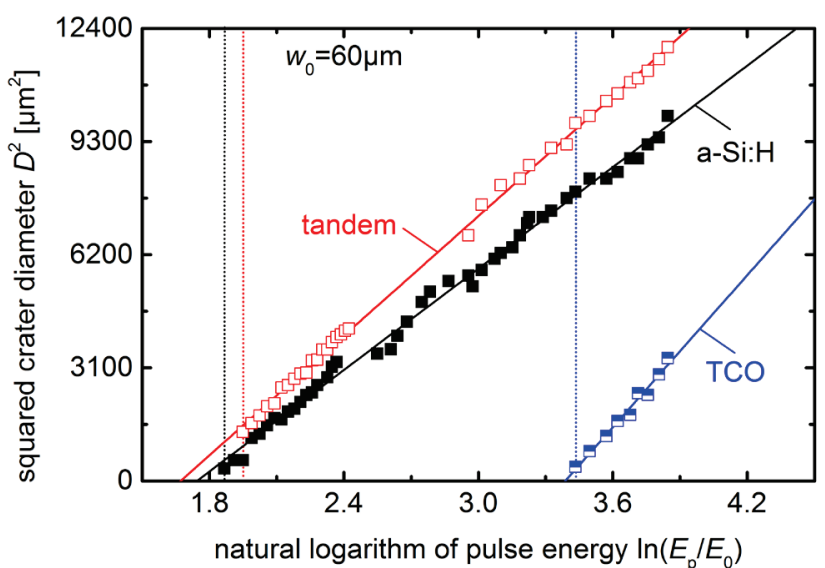

Fig. 5 Liu plot of a-Si:H p-i-n solar cell absorber (a) and tandem material ( $\square$ ) for a laser beam spot radius $w_{0}$ of $60 \mu \mathrm{m}$. Half-filled squares correspond to TCO damage ablation values (for tandem absorber). Dashed lines mark the onset pulse energies where ablation occurs.

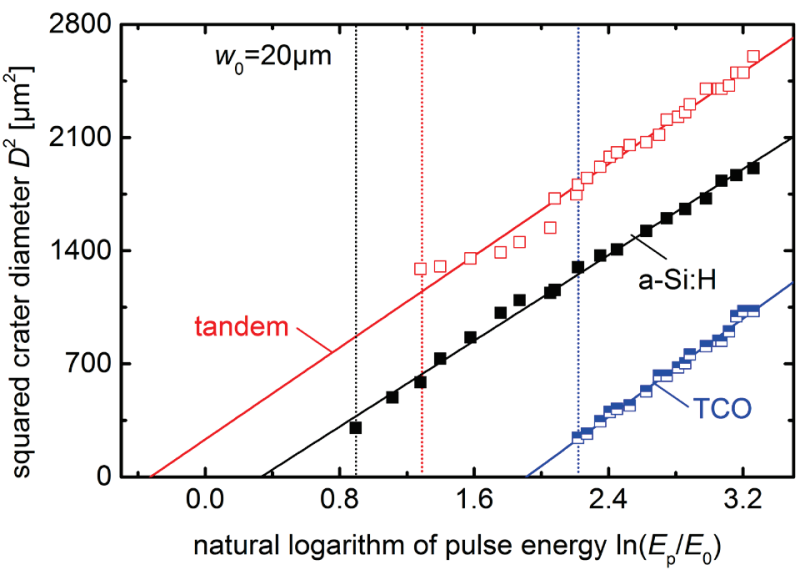

Fig. 6 Liu plot of a-Si:H p-i-n solar cell absorber (๘) and tandem material $(\square)$ for a laser beam spot radius $w_{0}$ of $20 \mu \mathrm{m}$. Half-filled squares correspond to TCO damage ablation values (for tandem absorber). Dashed lines mark the onset pulse energies where ablation occurs.

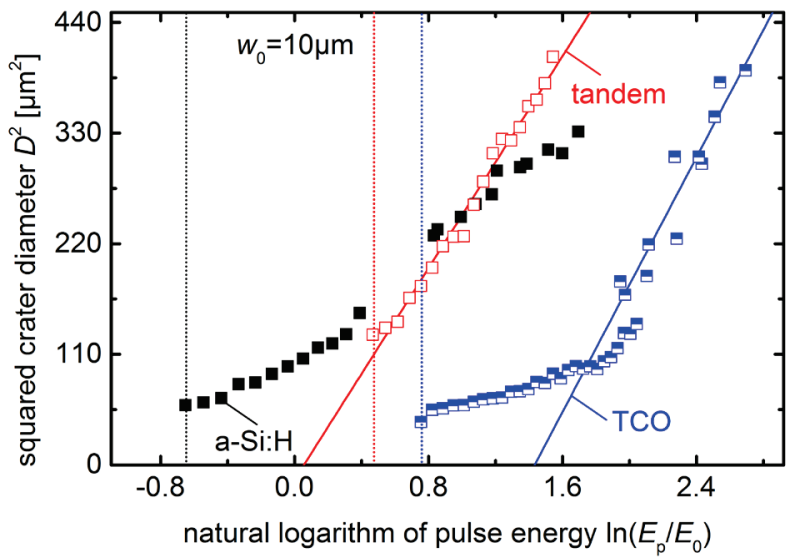

Fig. 7 Liu plot of a-Si:H p-i-n solar cell absorber ( $(\mathbf{)})$ and tandem material (口) for a laser beam spot radius $w_{0}$ of $10 \mu \mathrm{m}$. Half-filled squares correspond to TCO damage ablation values (for tandem absorber). Dashed lines mark the onset pulse energies where ablation occurs.

The intercept with the x-axis of each line fit will yield the so-called ablation threshold pulse energy $E_{\mathrm{th}}$. This is the 
minimal pulse energy at which processing of the material is induced. For laser-induced back-side ablation no crater formation is observed near $E_{\text {th }}$ and ablation only occurs above another certain threshold which is greater than the extrapolated pulse fluence $E_{\mathrm{th}}$. Below this so-called onset pulse energy $E_{\mathrm{p}, \text { on }}$ only layer bulging and blistering is observed. The dashed lines in Fig. 5-7 each mark the value of $E_{\mathrm{p}, \mathrm{on}}$. Furthermore, the beam spot radius $w_{0}$ can be evaluated from the line fit slope and can be compared with the measurement from the beam-profiler.

Figures 5 and 6 both show that for all three materials a linear correlation between $\operatorname{Ln}\left(E_{\mathrm{p}}\right)$ and $D^{2}$ is observed. It is interesting to note that for same pulse energies $E_{\mathrm{p}}$ the squared crater diameter $D^{2}$ is always higher for tandem absorber processing than for a-Si:H. One would expect that due to the higher thickness more energy is required to achieve a similar crater diameter. This is a clear hint for the mechanical nature of laser-induced back-side ablation. One explanation for this behavior could be that during the delamination of the absorber layer from the TCO material the thinner a-Si:H absorber is easily fractured leading to a smaller crater diameter compared to the thicker tandem layer with a higher mechanical stability. However, the required minimal $E_{\mathrm{p}, \text { on }}$ to achieve a proper ablation crater is increased for the higher film thicknesses (see dashed lines in Fig. 5-7). Figure 7 shows substantial deviations from the linear correlation of $\operatorname{Ln}\left(E_{\mathrm{p}}\right)$ vs. $D^{2}$ observed in both Figures 5 and 6. For a-Si:H processing and TCO ablation there are two different regimes, due to the change of slope, where the ablation mechanisms may be changed. Only tandem absorber processing shows a linear behavior with a slope corresponding to the measured beam spot radius $w_{0}$.

Due to the fact that no proper ablation can be realized close to $E_{\text {th }}$ and only bulging of the film occurs, interpretation of the onset pulse energy $E_{\mathrm{p}, \text { on }}$ (dashed lines in Fig. 5-7) gives additional information. To compare the ablation behavior between the three values of $w_{0}$ the onset pulse fluence $F_{\mathrm{p} \text {,on }}$ is used since it is corrected by the beam spot area $\left(F_{\mathrm{p}, \mathrm{on}}=2 E_{\mathrm{p}, \mathrm{on}} / \pi w_{0}^{2}\right)$. Table 2 shows a comparison of this value.

Table 2 Comparison of onset pulse fluence $F_{\mathrm{p}, \text { on }}$ for $300 \mathrm{~nm}$ thick a-Si:H absorber layer and $1.4 \mu \mathrm{m}$ thick tandem absorber on $\mathrm{SnO}_{2}: \mathrm{F}$ TCO material.

\begin{tabular}{cccc}
\hline $\begin{array}{c}w_{0} \text { from beam } \\
\text { profiler }[\mu \mathrm{m}]\end{array}$ & $\begin{array}{c}F_{\mathrm{p}, \text { on }} \text { a-Si } \\
{\left[\mathrm{J} / \mathrm{cm}^{2}\right]}\end{array}$ & $\begin{array}{c}F_{\mathrm{p}, \text { on }} \text { tandem } \\
{\left[\mathrm{J} / \mathrm{cm}^{2}\right]}\end{array}$ & $\begin{array}{c}F_{\mathrm{p}, \text { on }} \text { TCO } \\
{\left[\mathrm{J} / \mathrm{cm}^{2}\right]}\end{array}$ \\
\hline$\sim 60$ & 0.11 & 0.124 & 0.55 \\
\hline$\sim 20$ & 0.39 & 0.57 & 1.46 \\
\hline$\sim 10$ & 0.33 & 1.02 & 1.35 \\
\hline
\end{tabular}

The onset pulse fluence $F_{\mathrm{p}, \text { on }}$ increases when $w_{0}$ is decreased. However, for amorphous silicon and TCO the values are the highest for processing with $w_{0}=20 \mu \mathrm{m}$. A general correlation between the beam spot diameter and the onset fluence of a-Si:H on $\mathrm{SnO}_{2}: \mathrm{F}$ was also observed by Bovatsek et. al [2]. In our case, a possible reason for the decrease of $F_{\mathrm{p} \text {,on }}$ when $w_{0}=10 \mu \mathrm{m}$ is used could be the change of ablation behavior (cf. Fig. 7).

The increase of the onset fluence is much more pronounced for tandem layer ablation where $F_{\mathrm{p}, \text { on }}$ increases from $0.124 \mathrm{~J} / \mathrm{cm}^{2}$ to $1.02 \mathrm{~J} / \mathrm{cm}^{2}$. Like before, we can attribute this to the driving mechanisms of laser-induced back-side ablation. Since most of the laser pulse energy is absorbed in a confined region at the TCO/absorber interface, with decreasing $w_{0}$ the radial extent of this region decreases as well. From linear elastic fracture mechanics the minimal required mechanical stress for crack propagation between absorber and TCO can be described by the Griffith criterion [11], assuming the initial crack length is related to the spot size. Independent from the crack geometry the criterion always states that the stress necessary for crack propagation is increased for decreasing crack length (and therefore decreased spot size). For filmside stress-assisted laser ablation of CIGS Buzás et. al stated that the criterion is determining the final crater diameter [12]. Additionally, from the onset fluences for TCO it can be seen that the difference between the onset fluence of tandem ablation and TCO ablation is the lowest for scribing with $w_{0}=10 \mu \mathrm{m}$. This means the process window for selective removal of silicon is decreased with decreasing $w_{0}$.

\subsection{Scribe width reduction}

The determination of the different fluence regimes was used for a geometrical scribe width minimization. For this, the various onset fluences $F_{\mathrm{p} \text {,on }}$ are used as the lower limit with minimal crater diameter $D$. Since in the previous section single spot ablation was investigated the maximum feed-rate $v$ of the machine was used to achieve a high separation of the individual ablation craters. Now to create a continuous line $v$ is adjusted accordingly. The pulse energy $E_{\mathrm{p}}$ is then adjusted until a visually optimized scribe line with a minimal scribe width $w_{\mathrm{P} 2}$ is achieved. An optimized line is defined by a scribe line created with processing parameters that will lead to minimal signs of bulging at the scribe edges and low TCO damaging inspected by optical microscopy (used method: focusing plane sweep or transmitted light modus).

Figure 8 shows optical microscope images of visually optimized scribes for $300 \mathrm{~nm}$ a-Si:H absorber processing.
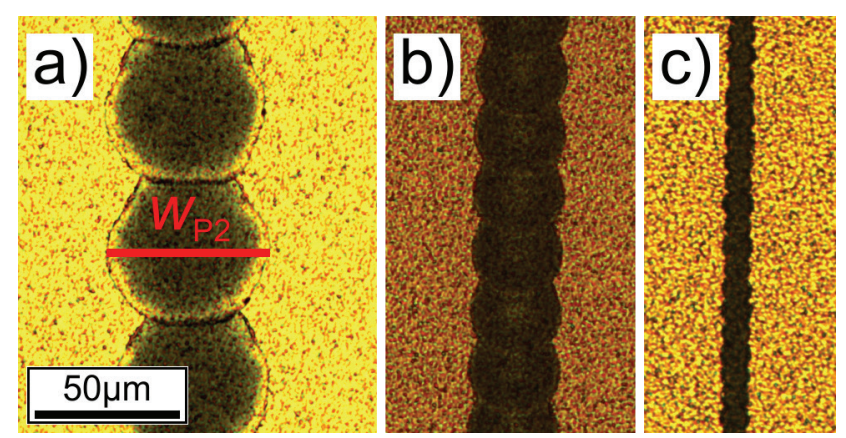

Fig. 8 Optical images of P2 scribe width optimization on $300 \mathrm{~nm}$ thick a-Si:H p-i-n solar cell material on $\mathrm{SnO}_{2}: \mathrm{F}$ TCO. Parameters: a) $w_{0}=60 \mu \mathrm{m}, F_{\mathrm{p}}=0.26 \mathrm{Jcm}^{-2}$ b) $w_{0}=20 \mu \mathrm{m}, F_{\mathrm{p}}=0.62 \mathrm{Jcm}^{-2}$ c) $w_{0}=10 \mu \mathrm{m}, F_{\mathrm{p}}=0.48 \mathrm{Jcm}^{-2} . \mathrm{A}$ clear correlation between $2 w_{0}$ and $w_{\mathrm{P} 2}$ can be seen.

The visually optimized scribe width nicely correlates with the used beam spot size $2 w_{0}$. But when comparing the required pulse fluences $F_{\mathrm{p}}$ of $0.26 \mathrm{Jcm}^{-2}, 0.62 \mathrm{Jcm}^{-2}$, and 
$0.48 \mathrm{Jcm}^{-2}$ for the spot radii $w_{0}$ of $60 \mu \mathrm{m}, 20 \mu \mathrm{m}$, and $10 \mu \mathrm{m}$ with $F_{\mathrm{p} \text {,on }}$ from Table 2 they are all shifted towards higher values. This was necessary to stabilize the process against any local change of the material properties and possible pulse-to-pulse variations of the laser source. Clean ablation without bulging at the scribe edge was accomplished for all three values of $w_{0}$. A scribe width $w_{\mathrm{P} 2}$ below $10 \mu \mathrm{m}$ is achieved for scribing with $w_{0}=10 \mu \mathrm{m}$.

Figure 9 shows optical microscope images of the visually optimized processing parameter for scribe width reduction of a $1.4 \mu \mathrm{m}$ thick tandem absorber layer using the same processing setup as before.

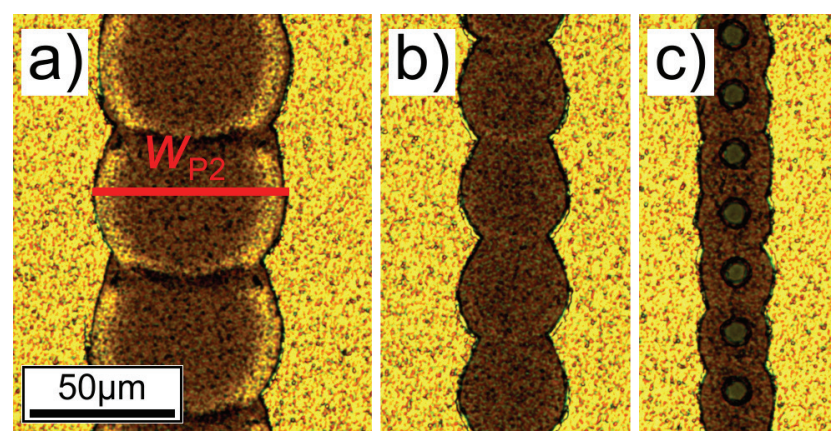

Fig. 9 Optical images of P2 scribe width optimization on $1.4 \mu \mathrm{m}$ thick tandem solar cell material on $\mathrm{SnO}_{2}: \mathrm{F} \mathrm{TCO}$. Parameters: a) $w_{0}=60 \mu \mathrm{m}, F_{\mathrm{p}}=0.28 \mathrm{Jcm}^{-2}$ b) $w_{0}=20 \mu \mathrm{m}$, $F_{\mathrm{p}}=0.92 \mathrm{Jcm}^{-2}$ c) $w_{0}=10 \mu \mathrm{m}, F_{\mathrm{p}}=1.5 \mathrm{Jcm}^{-2}$. No significant width reduction of $w_{\mathrm{P} 2}$ was achieved from $\mathrm{b}$ ) to $\mathrm{c}$ ).

These parameter yield a larger scribe width $w_{\mathrm{P} 2}$ compared to processing of $300 \mathrm{~nm}$ a-Si:H material from Fig. 8. This was already indicated from the ablation behavior characterization (see Fig. 5-7). Another finding is the deviation between beam radius reduction and scribe width reduction from $b$ ) to $c$ ). There is no significant additional width reduction achieved. Furthermore, for the smallest beam spot size in c) it was not possible to achieve a proper P2 scribe without partial ablation of the underlying TCO layer. This can be associated with the mentioned small process window due to the low difference between $F_{\mathrm{p}, \text { on }}$ for absorber ablation and TCO ablation (see Table 2). Due to the pulse overlap it is possible that this difference is getting even smaller since the TCO layer can be preheated by the previous laser pulses. Further experiments with thicker tandem absorber layers of $3.5 \mu \mathrm{m}$ confirmed even higher constraints on minimal achievable $w_{\mathrm{P} 2}$. For this material type it was not even possible to reduce $w_{\mathrm{P} 2}$ from processing with $w_{0}=60 \mu \mathrm{m}$ to $w_{0}=20 \mu \mathrm{m}$. Most likely, $F_{\mathrm{p}, \text { on }}$ is increased for this material type as well. This is in accordance with our previous findings and shows that the thickness of the absorber layer is important to be considered for scribe width reduction with laser-induced back-side ablation.

\subsection{Electrical properties}

For determination of the parasitic series resistance $R_{\mathrm{s}, \mathrm{P} 2}$ Transmission Line Method (TLM) measurements were carried out as a function of the pulse fluence $F_{\mathrm{p}}$. The feed-rate $v$ and pulse repetition frequency $f_{\mathrm{PRF}}$ was taken from the respective visually optimized scribe (see Fig. 8 \&
9). Figure 10 shows a plot for processing of a-Si:H material with different laser spot radii $w_{0}$.

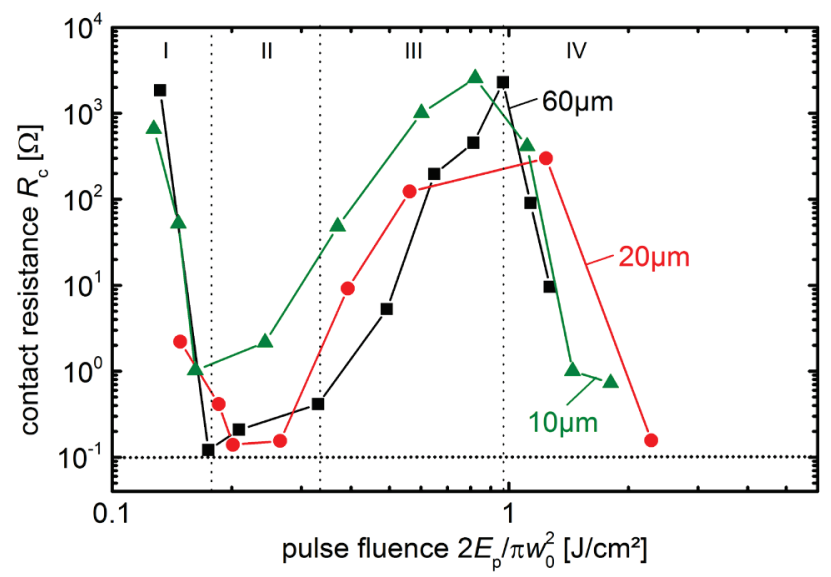

Fig. 10 Contact resistance $R_{\mathrm{c}}$ of a $300 \mathrm{~nm}$ thick a-Si:H absorber layer from TLM measurements vs. pulse fluence $F_{\mathrm{p}}$ at fixed feed-rate $v$ and repetition frequency $f_{\mathrm{PRF}}$ for different processing laser beam radii $w_{0}$ of $60 \mu \mathrm{m}(\mathbf{\square})$, $20 \mu \mathrm{m}(\bullet)$, and $10 \mu \mathrm{m}(\boldsymbol{\Delta})$. The distance $d$ between the contacts as well as the contact width $W$ was $1 \mathrm{~cm}$.

It can be seen that the behavior is very similar for all three used spot sizes and we can define different regions to describe the trends marked by the dashed lines exemplary for processing with $w_{0}=60 \mu \mathrm{m}(\mathbf{\square})$. Below $0.2 \mathrm{Jcm}^{-2}$ (region I) the contact resistance $R_{\mathrm{c}}$ is very high since the scribe line is discontinuous and the contact area $A=w_{\mathrm{P} 2} \cdot W$ is very small. Then $R_{\mathrm{c}}$ rapidly decreases exhibiting a minimum with a comparatively low resistance (region II). The extent of this region defines the stability window for the P2 process. Next, $R_{\mathrm{c}}$ increases with increasing fluences (region III) but decreases again above a certain threshold (region IV). Optical microscope images (not shown here) revealed an increase of ablation debris beside the scribe in the third region. Furthermore, damages of the TCO layer are observed. In most cases in the fourth region, even TCO ablation occurs. The decrease of $R_{\mathrm{c}}$ in region IV could be explained by the removal of surface residuals within the scribe due to increasing pulse overlap (fixed $v$ and $f_{\mathrm{PRF}}$ ). The sub-threshold fluence of the next laser pulse is sufficiently high to remove debris from the TCO surface at the location of the previous pulse.

When comparing the resistance values for the different laser beam radii it can be seen that a narrowing process window for higher focusing is observed (extent of region II). Furthermore, in average, an increase of $R_{\mathrm{c}}$ for decreasing $w_{0}$ can be seen. This is especially important in region II where the values for $w_{0}=10 \mu \mathrm{m}$ are strongly increased. Figure 11 shows a plot of the contact resistances $R_{\mathrm{c}}$ for processing of tandem absorber with fixed $v$ and $f_{\mathrm{PRF}}$ chosen according to the visually optimized scribe parameters for the different $w_{0}$ (compare Fig. 9). 


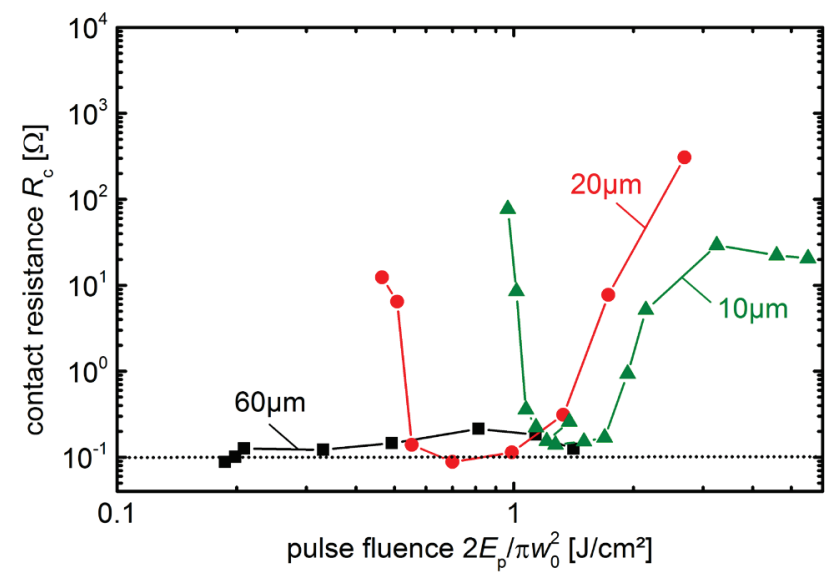

Fig. 11 Contact resistance $R_{\mathrm{c}}$ of a $1.4 \mu \mathrm{m}$ thick tandem absorber layer from TLM measurements vs. pulse fluence $F_{\mathrm{p}}$ at fixed feed-rate $v$ and repetition frequency $f_{\mathrm{PRF}}$ for different processing laser beam radii $w_{0}=60 \mu \mathrm{m}(\boldsymbol{\square})$, $20 \mu \mathrm{m}(\bullet)$, and $10 \mu \mathrm{m}(\boldsymbol{\Delta})$. Distance $d$ between the contacts as well as the contact width $W$ was $1 \mathrm{~cm}$. For comparison, scales are the same as in Fig. 10.

The trends show similarities to the plot from Figure 10 and the different regions can be found accordingly. Only for processing with $w_{0}=60 \mu \mathrm{m}(\boldsymbol{\bullet})$ a very large region II is obtained and the magnitude of increase in region III is rather low. Furthermore, a shift of region II to higher pulse fluences is observed for processing with $w_{0}=20 \mu \mathrm{m}$ and $10 \mu \mathrm{m}$ due to the increasing onset fluence for these spot sizes. In terms of process stability, it can be seen that the extent of region II is decreasing with decreasing $w_{0}$.

One explanation for the rise of $R_{\mathrm{c}}$ in the third region is possible deterioration of the TCO layer and increasing debris redeposition within the scribe as it was already shown by $\mathrm{Ku}$ et. al [4]. To investigate this, further experiments under vacuum conditions were carried out. It is well-known in literature that the pressure has a significant impact on the laser plasma particle distribution/velocities and therefore on the ablation debris [13]. Experiments of P2 processing on tandem absorbers were conducted with similar laser parameters and a beam spot radius of $w_{0}=20 \mu \mathrm{m}$ according to the pulse fluences from Fig. $11(\bullet$ line). The difference to the previous experiment is that processing was also done at vacuum conditions with a pressure of $1.5 \times 10^{-5}$ mbar. Figure 12 shows the TLM measurement comparing both processing conditions.

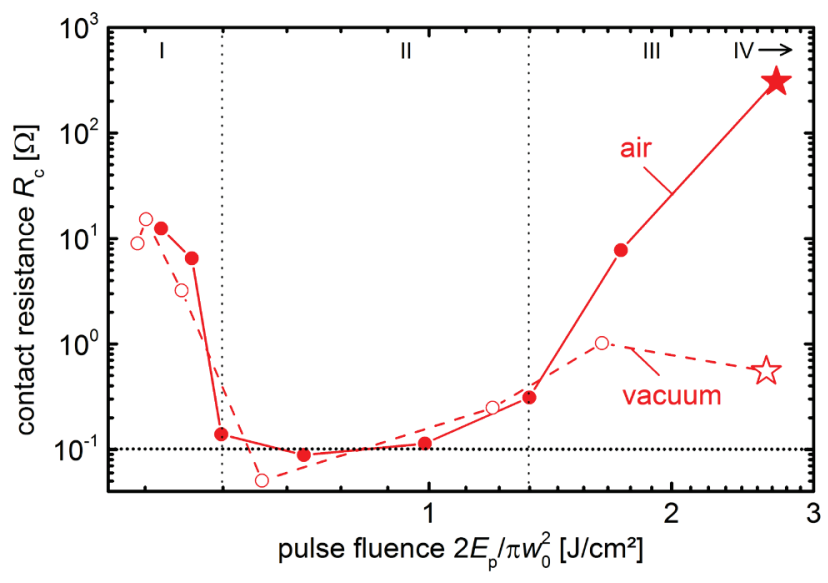

Fig. 12 Contact resistance $R_{\mathrm{c}}$ of a $1.4 \mu \mathrm{m}$ thick tandem absorber layer from TLM measurements vs. pulse fluence $F_{\mathrm{p}}$ and fixed feed-rate $v$ for a processing laser beam radius of $20 \mu \mathrm{m}$ in air $(\bullet)$ and at a pressure of $1.5 \times 10^{-5} \mathrm{mbar}(\circ)$. Distance $d$ between the contacts as well as the contact width $W$ was $1 \mathrm{~cm}$. Region IV is outside the processing parameter spectrum. Stars mark the parameter where optical microscopy was evaluated after back-contact deposition.

Both samples exhibit the same behavior until the third region (III). Here, the sample processed under vacuum conditions shows only a slight increase of $R_{\mathrm{c}}$ whereas the sample processed in air exhibits a huge increase. Figure 13 shows optical microscope images for the two processing parameters marked with stars in Figure 12.

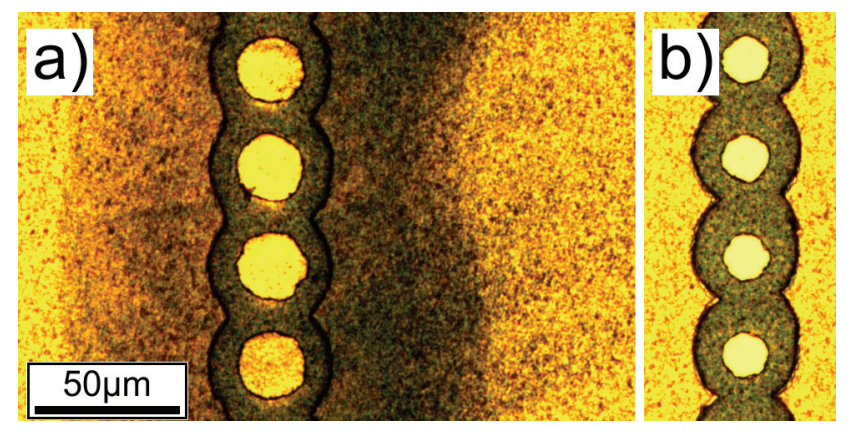

Fig. 13 Optical images of P2 scribes of $1.4 \mu \mathrm{m}$ thick tandem solar cell material on $\mathrm{SnO}_{2}: \mathrm{F}$ TCO after back-contact deposition. Parameters: a) according to $\star$ (filled-star), and $b$ ) matching with is (empty star) from Fig. 12. Differences in scribe width are due to slight differences in pulse fluences.

Visual inspection with optical microscopy reveals a greatly reduced debris redeposition along the scribe edge for the sample processed in vacuum (Figure 13(b)) while high amount of residuals are observed for processing in ambient atmosphere (Figure 13(a)). Therefore, the high increase in region III for samples processed in air can be owed to the increase of debris redeposition. However, a slight increase is observed for vacuum processed samples as well which could be explained by TCO layer ablation, and minor debris redeposition.

To take a closer look at the electrical properties, for better comparison, all minimal values of $R_{\mathrm{c}}$ are plotted in 
Table 3 for processing of both absorber materials from Figure 10 and 11.

Table 3 Minimal contact resistance values $R_{\mathrm{c}, \min }$ for $\mathrm{P} 2$ processing of a-Si:H and tandem absorber layers on $\mathrm{SnO}_{2}: \mathrm{F}$ TCO with different beam spot radii $w_{0}$. ${ }^{*}$ No continuous line, single spots.

\begin{tabular}{ccccc}
\hline $\begin{array}{c}\text { Absorber type } \\
\text { (thickness) }\end{array}$ & $\begin{array}{c}\text { Radius } \\
w_{0}[\mu \mathrm{m}]\end{array}$ & $\begin{array}{c}\text { Fluence } \\
F_{\mathrm{p}} \\
{\left[\mathrm{J} / \mathrm{cm}^{2}\right]}\end{array}$ & $\begin{array}{c}\text { Width } \\
w_{\mathrm{P} 2} \\
{[\mu \mathrm{m}]}\end{array}$ & $\begin{array}{c}R_{\mathrm{c}, \mathrm{min}} \\
{[\mathrm{m} \Omega]}\end{array}$ \\
\hline a-Si:H $(300 \mathrm{~nm})$ & 60 & 0.17 & $30 *$ & $121 \pm 2$ \\
\hline a-Si:H $(300 \mathrm{~nm})$ & 20 & 0.2 & 16 & $140 \pm 21$ \\
\hline a-Si:H $(300 \mathrm{~nm})$ & 10 & 0.16 & 6 & $1024 \pm 6$ \\
\hline tandem $(1.4 \mu \mathrm{m})$ & 60 & 0.19 & 40 & $88 \pm 5$ \\
\hline tandem $(1.4 \mu \mathrm{m})$ & 20 & 0.7 & 36 & $90 \pm 4$ \\
\hline tandem $(1.4 \mu \mathrm{m})$ & 10 & 1.5 & 24 & $152 \pm 3$ \\
\hline
\end{tabular}

In most cases the value of $F_{\mathrm{p}}$ that belongs to the minimal resistance $R_{\mathrm{c}, \text { min }}$ differ from the visually optimized values (see Fig. 8 and 9). This shows that visual evaluation of the scribe lines alone is not sufficient to achieve optimized electrical properties and needs to be considered. It is interesting to note that values of $R_{\mathrm{c}, \text { min }}$ for processing of tandem absorber are all in the same value range while for the a-Si:H absorber $R_{\mathrm{c}, \mathrm{min}}$ is strongly increased for processing with $w_{0}=10 \mu \mathrm{m}$. This cannot be described just by the contact area reduction due to the very low scribe width $w_{\mathrm{P} 2}$. Thus, a change of the specific contact behavior $\rho_{\mathrm{c}}$ is possible.

To see if the processing geometry has an impact on $\rho_{c}$ or changes are only due to the contact geometry we numerically evaluated equation (4) to determine $\rho_{\mathrm{c}}$. Table 4 shows the results of this numerical evaluation.

Table 4 Calculation of the specific contact resistance $\rho_{c}$ from Eq. (4) for $\mathrm{P} 2$ processing of a-Si:H and tandem absorber layers on $\mathrm{SnO}_{2}: \mathrm{F}$ TCO with the electrically optimal processing parameters from Table 3. Parameters are: a-Si:H layers (row 1-3) and tandem layers (row 4-6)

\begin{tabular}{ccc}
\hline $\begin{array}{c}\text { Sheet resistance } \\
R_{\mathrm{SH}}[\Omega]\end{array}$ & $\begin{array}{c}\text { Contact } \\
\text { resistance } \\
R_{\mathrm{c}, \mathrm{min}}[\mathrm{m} \Omega]\end{array}$ & $\begin{array}{c}\text { Specific contact } \\
\text { resistance } \rho_{\mathrm{c}} \\
{\left[\Omega \mathrm{mm}^{2}\right]}\end{array}$ \\
\hline $7.68 \pm 0.017$ & $121 \pm 2$ & 0.034 \\
\hline $7.6 \pm 0.02$ & $140 \pm 21$ & 0.021 \\
\hline $7.57 \pm 0.01$ & $1024 \pm 6$ & 0.061 \\
\hline $8.57 \pm 0.01$ & $88 \pm 5$ & 0.031 \\
\hline $8.67 \pm 0.01$ & $90 \pm 4$ & 0.028 \\
\hline $8.57 \pm 0.01$ & $152 \pm 3$ & 0.034 \\
\hline
\end{tabular}

The TCO sheet resistance $R_{\mathrm{SH}}$ was extracted from the slope of the TLM measurements according to Eq. (3). Comparing the first three values of $\rho_{\mathrm{c}}$ from Table 4 for a-Si:H absorber processing we can see that the deviations are quite substantial which indicate that there are changes of the contact properties. For very narrow scribe lines a strong increase not only for the $R_{\mathrm{c}}$ but also for $\rho_{\mathrm{c}}$ was observed.
For processing of tandem absorber layers (last three rows) $\rho_{\mathrm{c}}$ is almost constant $\left(0.028 \Omega \mathrm{mm}^{2}-0.034 \Omega \mathrm{mm}^{2}\right)$ indicating contact properties are independent from the processing geometry. Further investigations close to the contact resistance minimum (region II) are necessary to characterize the specific contact properties over a broader range of values.

Now to obtain the optimal trade-off between increase of Ohmic losses from increasing values of $R_{\mathrm{c}, \min }$ vs. gain of active area $w_{\mathrm{a}}$ (see Fig. 2) from the reduction of $w_{\mathrm{P} 2}$ the model from Gupta et. al [1] can be extended to account for $\mathrm{P} 2$ series resistance losses. We can define a loss fraction $f_{\mathrm{P} 2}$ with setting the power losses from the series resistance $R_{\mathrm{s}, \mathrm{P} 2}$ $\left(P_{\mathrm{P} 2}\right)$ at the maximum power point (MPP) in relation with the maximum power $\left(P_{\max }=U_{\mathrm{MPP}} \times I_{\mathrm{MPP}}\right)$ if no series connection losses were apparent. The following equation shows this relation,

$$
f_{\mathrm{P} 2}=\frac{P_{\mathrm{P} 2}}{P_{\max }}=-w_{\mathrm{a}} R_{\mathrm{s}, \mathrm{P} 2}^{\prime} \frac{J_{\mathrm{MPP}}}{U_{\mathrm{MPP}}}
$$

Here, $w_{\mathrm{a}}$ is the active cell width, $J_{\mathrm{MPP}}$ and $U_{\mathrm{MPP}}$ are the current density and voltage in the maximum power point. The value $R_{\mathrm{s}, \mathrm{P} 2}^{\prime}=R_{\mathrm{c}, \min } \cdot W$ is the $\mathrm{P} 2$ processing series resistance scaled to the cell stripe length. Figure 14 shows calculations for a tandem module with different P2 scribe widths $w_{\mathrm{P} 2}$ and the corresponding $R_{\mathrm{c}, \min }$ to estimate their influence on the overall module loss fraction $f$. As reference, a calculation with processing parameters commonly used in industry is plotted for comparison assuming an P2 scribe width $w_{\mathrm{P} 2}$ of $90 \mu \mathrm{m}$ [14] and an series resistance $R_{\mathrm{s}, \mathrm{P} 2}^{\prime}$ of $100 \mathrm{~m} \Omega \mathrm{cm}$.

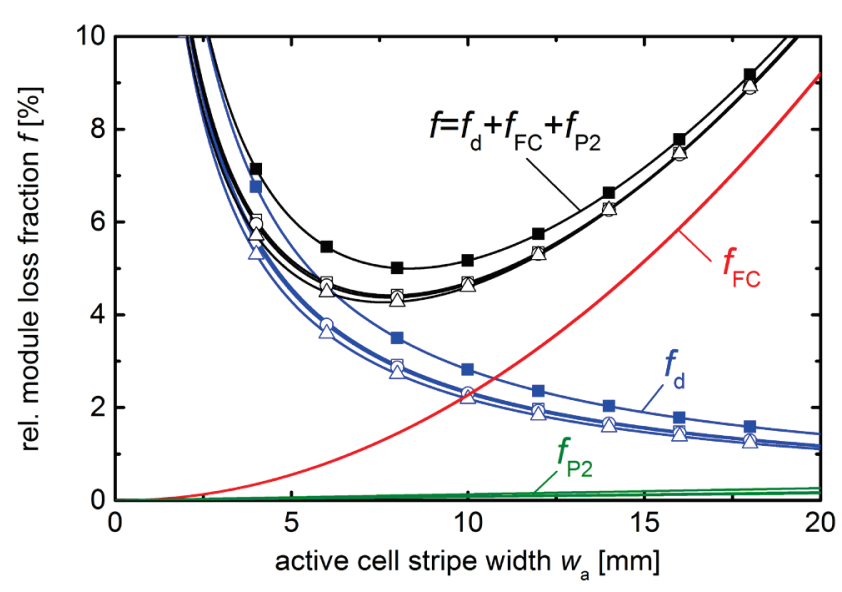

Fig. 14 Module loss fraction calculation for a tandem solar cell with different $\mathrm{P} 2$ scribe widths $w_{\mathrm{P} 2}$ and corresponding $R_{\mathrm{S}, \mathrm{P} 2}^{\prime}$ values from measurement. Processing parameters are $\left(w_{\mathrm{P} 2} / R_{\mathrm{s}, \mathrm{P} 2}^{\prime}\right): 40 \mu \mathrm{m} / 88 \mathrm{~m} \Omega \mathrm{cm}(\square), 36 \mu \mathrm{m} / 90 \mathrm{~m} \Omega \mathrm{cm}$ $(\circ), 24 \mu \mathrm{m} / 152 \mathrm{~m} \Omega \mathrm{cm}(\Delta)$, and typical reference values assuming $90 \mu \mathrm{m} / 100 \mathrm{~m} \Omega \mathrm{cm}(\mathbf{\square})$. The remaining part of the interconnection width $w_{\mathrm{d}}$ was kept at $200 \mu \mathrm{m}$. For $f_{\mathrm{TCO}}$ a sheet resistance of $R_{\mathrm{SH}}=8 \Omega$ was used. Solar cell parameters are: $J_{\mathrm{MPP}}=-9.7 \mathrm{~mA} / \mathrm{cm}^{2}$ and $U_{\mathrm{MPP}}=1.1 \mathrm{~V}$

We can see that there is only a slight variation between the electrically optimized P2 processing parameters for $w_{0}$ of $60 \mu \mathrm{m}, 20 \mu \mathrm{m}$, and $10 \mu \mathrm{m}(\square, \circ$, and $\Delta)$. The biggest difference is between the reference parameter $(\boldsymbol{\square})$ and the 
optimized ones. A relative reduction of module losses by $1 \%$ is predicted at the optimal cell stripe width with minimal overall losses $f$. A similar calculation was also done for the scribe width reduction of a-Si:H absorber layers with the electrical parameter for the optimized processes from Table 2. Figure 15 shows a plot with these calculations.

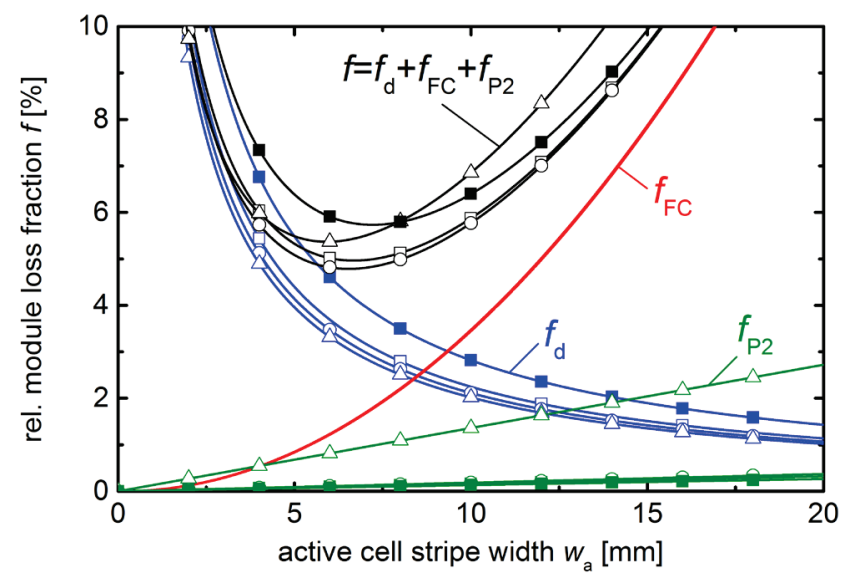

Fig. 15 Module loss fraction calculation for an a-Si:H solar cell with different $\mathrm{P} 2$ scribe widths $w_{\mathrm{P} 2}$ and corresponding $R_{\mathrm{s}, \mathrm{P} 2}^{\prime}$ values from measurement. Processing parameters are $\left(w_{\mathrm{P} 2} / R_{\mathrm{s}, \mathrm{P} 2}^{\prime}\right): 30 \mu \mathrm{m} / 121 \mathrm{~m} \Omega \mathrm{cm}(\square), 16 \mu \mathrm{m} / 140 \mathrm{~m} \Omega \mathrm{cm}$ (०), $6 \mu \mathrm{m} / 1024 \mathrm{~m} \Omega \mathrm{cm}(\Delta)$, and typical reference values assuming $90 \mu \mathrm{m} / 100 \mathrm{~m} \Omega \mathrm{cm}(\mathbf{\square})$. The remaining part of the interconnection width $w_{\mathrm{d}}$ was kept at $200 \mu \mathrm{m}$. For $f_{\mathrm{TCO}}$ a sheet resistance of $R_{\mathrm{SH}}=8 \Omega$ was used. Solar cell parameters are: $J_{\mathrm{MPP}}=-10.17 \mathrm{~mA} / \mathrm{cm}^{2}$ and $U_{\mathrm{MPP}}=0.765 \mathrm{~V}$

The general behavior is quite similar to the calculations from Figure 14 except for the parameters from processing with $w_{0}=10 \mu \mathrm{m}$. The $\mathrm{P} 2$ loss fraction $f_{\mathrm{P} 2}$ is substantially increased. For this case, the width reduction is actually counterproductive when considering the overall losses. Overall losses $f$ tend to decrease from the reference parameters ( $\square)$ to scribing with the optimized values of $w_{0}=60 \mu \mathrm{m}(\square)$ and reach the minimum for $w_{0}=20 \mu \mathrm{m}(\circ)$ but then increase again for processing with $w_{0}=10 \mu \mathrm{m}(\Delta)$. Bearing this in mind a reduction of the overall losses is still possible and is in the range of approx. $1 \%$. The reason for the increase of overall losses for $w_{0}=10 \mu \mathrm{m}$ processing $(\Delta)$ can be owed to the strong increase of the $f_{\mathrm{P} 2}$ loss fraction which is significantly increased for this case.

\section{Conclusion}

We showed that for laser-induced back-side ablation of thin-film silicon layers on TCO front-contact material the ablation behavior strongly depends on the used laser beam spot size and/or layer thicknesses. A method, commonly used in laser processing, proposed by Liu has proven to be not fully suitable for the characterization. Evaluation of the onset pulse fluence where proper ablation occurs provides additional information and showed that there are limits to width reduction due to increase of said value with decreasing laser spot sizes. One explanation for the strong dependence of the ablation behavior on the spot size and layer thickness can be identified by the mostly mechanically driven mechanism of laser-induced back-side ablation where the main part of the laser pulse energy is absorbed in a very confined region in the silicon starting at the absorber/TCO interface. Mechanical stresses lead to a structural disintegration and expulsion of the mostly solid absorber material [6]. These stresses are highly dependent on the processing geometry [11] and could explain the observed results. For scribe width reduction we can conclude that very thin scribes are only possible for thin absorber layers. Different beam shaping concepts like top-hat profiles, line shaped spots, or square spots could improve the selectivity of the removal process but are somehow limited by the minimal achievable spot sizes. Process stability issues with regards to the reduced depth-of-focus could be problematic for small spot sizes.

Investigations on the electrical properties of the visually optimized processing parameters were conducted. The minimal achievable contact resistances $R_{\mathrm{c}, \min }$ for processing of a-Si:H were somewhat higher than for tandem absorber which was accounted to changes of the specific contact resistance $\rho_{c}$. For tandem absorber processing a regime with low resistance values could be found for all three processing laser beam spot sizes. But, the scribing parameters for electrically optimal scribe lines differ from the visually evaluated optimal lines. It is therefore necessary to conduct an electrical evaluation of the contact properties to obtain the optimal processing parameters.

Finally, the measured values of $R_{\mathrm{S}, \mathrm{P} 2}$ together with the achieved scribe width $w_{\mathrm{P} 2}$ were used to calculate the possible reduction of relative overall modules losses of a thin-film a-Si:H solar module as well as tandem solar module which are predicted to be in the range of at least $1 \%$. For calculations of tandem module losses, the losses created by the P2 series resistance are almost negligible compared to the gain of active area which gives motivation for further width reductions. Calculations for the a-Si:H module showed that depending on the used process the series resistance loss fraction $f_{\mathrm{P} 2}$ can be significantly increased and be higher than the decrease of the dead area fraction $f_{\mathrm{d}}$. In this case the scribe width reduction would be counterproductive. For processing of a-Si:H solar cell material an improvement of the specific contact resistance $\rho_{c}$ is therefore necessary to reduce the series resistance losses.

\section{Acknowledgments}

The authors would like to thank U. Rau for fruitful discussions. The authors would also like to thank A. Bauer, U. Gehards, G. Schöpe, and H. Siekmannn for sample preparation. This research has been financed by the "Bundesministerium für Umwelt, Naturschutz und Reaktorsicherheit" in the project "Laso", Contract No. 0325245E.

\section{References}

[1] Y. Gupta, H. Liers, S. Woods, S. Young, R. Deblasio, and L. Mrig: Proc. 16th PVSC (1982) p. 1092-1101.

[2] J. Bovatsek, A. Tamhankar, R.S. Patel, N.M. Bulgakova, and J. Bonse. Thin Solid Films, 518, (2010), 2897-2904.

[3] S. Lauzurica, and C. Molpeceres: Physics Procedia, 5, (2010) 277-284. 
[4] S. Ku, S. Haas, B. E. Pieters, U. Zastrow, A. Besmehn, Q. Ye, and U. Rau: Applied Physics A, 105(2), (2011) 355-362.

[5] K. Brecl, and M. Topič: Progress in Photovoltaics: Research and Applications, 16(6), (2008) 479-488.

[6] G. Heise, M. Domke, J. Konrad, S. Sarrach, J. Sotrop, and H. P. Huber: Journal of Physics D: Applied Physics, 45(31), (2012) 315303.

[7] H. Keppner, J. Meier, P. Torres, D. Fischer, and A. Shah: Applied Physics A: Materials Science and Processing, 69(2), (1999) 169-177.

[8] J. M. Liu: Optics letters, 7(5), (1982) 196-198.

[9] W. Shockley: "Research and investigation of inverse epitaxial UHF power transistors," Report No. A1TOR-64-207, September 1964.
[10] G. K. Reeves, and H. B. Harrison: IEEE Electron Device Letters, 3(5), (1982) 111-113.

[11]A. A. Griffith: Philosophical transactions of the royal society of London. Series A, 221, (1921) 163-198.

[12]A. Buzás, and Z. Geretovszky: Physical Review B Condensed Matter and Materials Physics, 85(24), (2012) 245304.

[13] S. Abdelli-Messaci, T. Kerdja, S. Lafane, S. Malek: Spectrochimica Acta Part B: Atomic Spectroscopy, 64(10), (2009), 968-973

[14]B. Frei, S. Schneeberger, and R. Witte: Proc. Of SPIE, 7920, (2011) 792011-792011-13.

(Received: August 22, 2013, Accepted: November 21, 2013) 